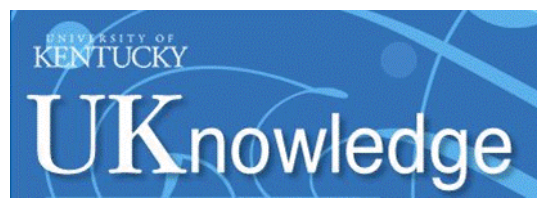

University of Kentucky

UKnowledge

\title{
A Research on Community-Based Livestock of Qinghai-Tibet Plateau
}

Ze Bai

Sichuan Academy of Grassland Sciences, China

Gang Liu

Sichuan Academy of Grassland Sciences, China

Qunying Zheng

Sichuan Academy of Grassland Sciences, China

Hongxuan Zhang

Sichuan Academy of Grassland Sciences, China

Ligang Dao

Sichuan Academy of Grassland Sciences, China

See next page for additional authors

Follow this and additional works at: https://uknowledge.uky.edu/igc

Part of the Plant Sciences Commons, and the Soil Science Commons

This document is available at https://uknowledge.uky.edu/igc/23/3-4-1/5

The XXIII International Grassland Congress (Sustainable use of Grassland Resources for Forage Production, Biodiversity and Environmental Protection) took place in New Delhi, India from November 20 through November 24, 2015.

Proceedings Editors: M. M. Roy, D. R. Malaviya, V. K. Yadav, Tejveer Singh, R. P. Sah, D. Vijay, and A. Radhakrishna

Published by Range Management Society of India

This Event is brought to you for free and open access by the Plant and Soil Sciences at UKnowledge. It has been accepted for inclusion in International Grassland Congress Proceedings by an authorized administrator of UKnowledge. For more information, please contact UKnowledge@lsv.uky.edu. 


\section{Presenter Information}

Ze Bai, Gang Liu, Qunying Zheng, Hongxuan Zhang, Ligang Dao, Xiaoyi Wang, Xiaode Zhang, and Zhi Lu 
Paper ID: 1426

Theme 3. Sustainability of grasslands- social and policy issues

Sub-theme 3.4. Improving grasslands through education and practice

\title{
A research on community-based livestock of Qinghai-Tibet Plateau
}

\author{
Ze Bai ${ }^{*}$, Gang Liu ${ }^{1}$, Qunying Zheng ${ }^{1}$, Hongxuan Zhang ${ }^{1}$, Ligang Dao ${ }^{1}$, Xiaoyi Wang ${ }^{2}$, Xiaode Zhang $^{3}$, Zhi Lv $^{4}$ \\ ${ }^{1 *}$ Sichuan Academy of Grassland Sciences, Chengdu, China \\ ${ }^{2}$ Chinese Academy of Social Sciences, Beijing, China \\ ${ }^{3}$ National School of Administration, Beijing, China \\ ${ }^{4}$ Peking University, Beijing, China
}

*Corresponding author e-mail : $\underline{350903876 @ q q . c o m}$

Keywords: Community capacity building, Grassland ecology, Main body to nomads, Mutual cooperation, Traditional culture

\section{Introduction}

Qinghai-Tibet Plateau locates in Southwestern China, covering the whole area of Tibet Autonomous Region, Qinghai Province, Southern part of Gansu Province, Northwestern part of Sichuan Province and Northwestern part of Yunnan Province, with an area of around 139.08 million hectares of natural grassland, accounting for 39\% of the total area of natural grassland in China. It is also the largest natural ecozones in China and one of the least disturbed regions by human activities, with its air, water sources, soil, grassland, wildlife in their pristine state.

Qinghai-Tibet Plateau is the native home for Tibetan people. Grassland animal husbandry is the foundation of the economy of QTP and the main source of livelihood for local nomadic people. During the long term of concerted evolution with the nature, Tibetan people living on Qinghai-Tibet Plateau have formed a uniquely holistic grassland ecological culture that is compatible with their production system and the ecosystem. The majority of Tibetan people observe Tibetan Buddhism. Their respect for nature and their belief in that all sentient beings are equal take deep root in their traditional culture. Their harmonious co-existence with nature exemplifies the eco-civilization ideas and provides a solid cultural foundation for both ecology conservation and featured animal husbandry development.

On Qinghai-Tibet Plateau, national policies and initiatives such as dual contract of livestock and forage, natural grassland vegetation recovery, returning grazing land to grassland, grassland ecosystem subsidy and rewarding mechanism have been implemented, playing an important role in promoting grassland ecosystem conservation and grassland animal husbandry development. However, since grassland animal husbandry is a complex system involving grassland, farm animal, environment, society, economy, culture, etc, there are still many outstanding problems to be solved.

\section{Materials and Methods}

Participatory approach and community development ideas, agricultural systematic engineering thinking are adopted for conducting this research.

\section{Results and Discussion}

Basic rationale: The research systematically looks into the interrelations of natural environment, geography, social history, economic development of Qinghai-Tibet Plateau, aiming to solve the bottleneck problem, i.e., the conflict between grassland ecology conservation and income generation of herders, by improving the production system structure and all factors' functional performance and increasing added value, transforming from the quantity-oriented growth model to quality and profit-oriented model.

The concept of Qinghai-Tibet Plateau community-based animal husbandry: Qinghai-Tibet Plateau community-based animal husbandry is a sustainable form of production organization model and lifestyle that is voluntarily accepted and practiced by a community of herders who live in a natural village and share common benefits, whose life and livelihood are based on local natural endowment and cultural heritage. With holistic correlation of community economy, culture and ecology, such production is operated on household-basis that is linked by reciprocity and cooperation.

\section{Outputs of Research:}

Adaptative natural rangeland utilization technology and model based on local culture: Conduction of research on natural grassland health assessment system, adaptative management technology integration and demonstration, degraded grassland recovery and improvement technology integration and demonstration. 
Ecologically safe forage production technology and model based on local forage species: Possible pollution and destruction were avoided by restraining from using pesticide, chemical fertilizers and large scale tilling for higher productivity, and awareness of possible eco-disasters brought by alien species were increased. Locally appropriate species of perennial and annual grass were selected and planted to have improved the forage production in the 8 communities.

Local animal heritage breeds protection and strengths utilization technology and model: Selections of prepotent sires of yaks and Tibetan sheep of local heritage breeds were conducted, and healthy livestock raising techniques and facilities were improved.

Local specialized animal products quality improvement technology and production model: The production process and technologies of traditional yak dairy/meat products and sheep meat products were improved. Herders now produce and process animal products with more added value in terms of improved packaging, branding and marketing.

Strategy of local human resource capacity building and participatory community action pilot: Community production organizations were established, including cooperatives, animal product processing plants, as well as herders' field schools, interest groups; and capacities of the herders, cooperative leaders, government officials, technical personnels were improved.

\section{Conclusion}

Under the unique environment of Qinghai-Tibet Plateau, the dynamic balance made by the concerted evolution of grassland, livestock and culture over the long haul, harsh climate conditions, complicated ecosystem, biodiversity and cultural diversity, the venerability and sensitivity of the ecosystem, interwoven together, understanding of the complexity and uniqueness of Qinghai-Tibet Plateau's natural and cultural systems is the prerequisite for the sustainable development of community-based animal husbandry.

The uniqueness and limitedness of the natural resources on Qinghai-Tibet Plateau determine that the production of animal husbandry and the quantity of animal products should not be market-driven or need-oriented, but must respect the foragelivestock balance, taking into consideration of the pressures on resource and environment. Product-oriented sales and marketing model are the guarantees for realizing the win-win situation between conservation and development.

Animal husbandry production, namely grazing under forage-livestock balance and natural resource management, includes labor and work for conserving the ecology, creating double values in both husbandry and environment protection. If the herders' double labor and work cannot be paid with reward equivalent to their contribution, they will compensate their inadequate labor income by their husbandry income, which inevitably leads to over-grazing. Establishing the subjectivity of herders in grassland conservation, and paying reasonable income compensation for their work effort in conserving the grassland ecology, providing support for the husbandry development are the innate demands of forming long-term mechanisms for community grassland resources management and ecology conservation.

The exclusive and irreplaceable nature of Qinghai-Tibet Plateau animal husbandry production determines that the production is a herders-centered production system, a lifestyle and a cultural form, especially a system with high degree of integration of economic value, ecological value and cultural value. It is neither possible for the fragile natural ecology, unique cultural and production system to bear over-industrialized marketisation, capitalization and scale development, nor is it appropriate to apply conventional model of attracting external investment, such as large capital's attempt to transform the traditional production and to marginalize the herders in the wealth generation process. The appropriate way is to respect the production and lifestyle of herders and the cultural traditions, and with the support from the government, to fully take advantage of local special strengths. These are the basic principles for choosing which direction and which path to go to develop Qinghai-Tibet Plateau animal husbandry.

It is not possible to change the innate traits of grassland animal husbandry and the nature endowment of Qinghai-Tibet Plateau. Therefore, the traditional production is not backward or advanced per se, but rather compatible with local natural resources and social-economic culture. It's not to scale up the small-sized and scattered animal husbandry production into large-scale ones, but to intensify the strengths, and to create and utilize a nitch market. The way of thinking is not to substitute the natural grazing type animal husbandry with high productivity animal husbandry because of its low feed conversion efficiency, but to sustain and benefit from its ecological strengths. It is not to single-mindedly apply the technology and development model from outside Qinghai-Tibet Plateau, but to work together with local herders, to discover the wisdom from each other, to understand each other's mentality, to search for the common understanding between different cultures and values, to explore the ways to development which are compatible to local situations, and to convert the qualities that are seen as disadvantages by conventional development viewpoints into developmental advantages, without having to disregard those qualities. 